\title{
Mechanical and electrical behaviours of polybutylene terephthalate/ polyethylene terephthalate blend nanotube composites
}

\author{
Rajakumar P R*, Dr Nanthini R. \\ Dept. of Chemistry, Government Arts College Chidambaram, Tamilnadu, India \\ Dept. of Chemistry, Pachayappa's College Chennai, Tamilnadu, India \\ *Corresponding author E-mail:prrajkkumar@gmail.com
}

\begin{abstract}
Polybutylene Terephthalate (PBT) / Polyethylene Terephthalate (PET) nanotube composite blend was fabricated using melt blending technique in a twin extruder. The blend composition was optimized at PBT-PET weight ratio of 80-20. The effect of incorporation of MWCNT on the mechanical, electrical properties of the nanotube composites blend has been investigated. Mechanical properties show marginal improvement in impact strength, but considerable improvement in tensile strength and flexural strength. Changes in electrical properties observed.
\end{abstract}

Keywords: Electrical Nanotube, mechanical, MWCNT, PBT, PET.

\section{Introduction}

Blending of two or more polymers has emerged as an established route to design tailor made polymeric materials with desired attributes for various high performance applications [1-4]. Different approaches such as use of compatibilising agents, copolymers, grafting agents, reactive extrusion etc., have been the commonly used techniques to modify the interfacial region between the blends and increase the compatibility [5,6].

More recently, PLS nanocomposites have attracted great interest both in industry and in academic, because they often exhibit remarkable improvements in properties when compared with virgin polymers. Layered silicates, with its inherent high aspect ratio ranging from 100 to 2000 offers more surface contact per unit filler within the polymer matrix resulting in enhanced performance characteristics with a minimum loading of 3-5 \% [7].

An intercalated structure results when the polymer penetrates into the galleries of the layered structure resulting in a highly ordered arrangement of alternating clay platelet and polymer layers. An exfoliated structure is formed when the layered silicates are delaminated. Large improvement in the mechanical properties is observed when clay platelets are well dispersed and exhibit an exfoliated morphology within the polymer matrix.

PBT is one of the engineering plastics which have good combination of properties such as rigidity, hardness, abrasion, solvent resistance, electrical insulation and high rates of cyrstallisation that allow short cycle times in injection moulding [8-10]. However, PBT is strongly notch sensitive, give low notched Izod impact strength [11, 12] and break in a brittle fashion when standard notched specimens are tested. The strong notch sensitivity of PBT can be eliminated by the incorporation of impact modifiers [13] such as, nanoclays or in general nanomaterials which increase the surface area which in turn increases the mechanical properties. Thus, polymer nanocomposites, at loading levels of 2-3\% of nanomaterials exhibit enhanced mechanical properties, improved thermal properties when compared with neat polymers or their blends [14]. The cost difference between the neat matrix and its polymer nanocomposites is about 10-15\%.

PET possesses good tensile strength, stiffness, excellent dimensional stability, excellent melt strength with slower crystallisation rate and high tear strength. PET also has good Izod impact strength even at low temperature. Heat deflection temperature HDT, of PET and PBT are same at $1.8 \mathrm{MPa}$. The Tg of PET is $80^{\circ} \mathrm{C}$ and that of PBT is $25^{\circ} \mathrm{C}$. PET belongs to the polyester group as PBT. Both PBT and PET form a well uniform phase on mixing.

Carbon nanotube is allotropes of carbon with a cylindrical nano structure. Nanotube name is derived from their size, since the diameter of a nanotube is in the order of a few nanometers [15]. A nanotube may consist of one tube of graphite called single walled nanotube, SWNT or a number of concentric tubes, called multi walled nanotube, MWNT. MWNT looks like a rope made of bundles of concentric SWNTs. The C-C bond length is $0.14 \mathrm{~nm}$ which is shorter than diamond indicating greater strength. This strength results from the covalent $\mathrm{sp} 2$ bonds formed between the individual 
carbon atoms [16]. Diamond is considered to be the hardest material. Now CNT are on par with diamonds in hardness [17] . MWCNT can be excellent conductor $[18,19]$.

CNT has variety of applications. Researchers and companies are working to use carbon nanotube in various fields. Attracted by the properties of CNT, efforts were taken in the present work to add nanotube with PBT-PET blend and to prepare exfoliated nanotube composites. Mechanical properties and electrical properties were carried out for the samples prepared with $0.15 \%, 0.30 \%$ and $0.45 \%$ weight ratios of carbon multi wall nanotube.

\section{Experimental}

\subsection{Materials}

The polymer matrix used in this research is a commercial PBT (DUPONT TM CRASTIN® S610SF NC010). PET was supplied by GE plastics. The CNT used was Sun Nano @ MWCNT with diameter ranging between 10-30 nm and appear as black powder. PBT was blended with PET in different ratios like 90-10, 80-20 and 70-30. From the experimental results, $80 \%$ weight of PBT gives better results with $20 \%$ weight of PET and it was considered as an optimized ratio. MWCNT is incorporated in the weight ratio of $0.15 \%, 0.30 \%$ and $0.45 \%$ with $80 \%$ PBT toughened by $20 \%$ PET.

\subsection{Preparation of blends}

Initially PBT and PET were blended without filler, to get 90-10, 80-20 and 70-30 weight ratio to establish optimized blend ratio. Based on the tensile and impact strength, the optimized percentage of PET is $20 \%$ by weight. Then PBT/PET 80:20 blend mixture was mixed with $0.15 \%, 0.30 \%$ and $0.45 \%$ weight ratios of carbon multi wall nanotube. PBT was dried at $100^{\circ} \mathrm{C}$ in an air circulated oven for 8 hours prior to blending. The blend was prepared via melt compounding method using twin screw extruder (Bersfort FRG Germany) at temperature range of $220^{\circ} \mathrm{C}$ with a screw speed of $150 \mathrm{rpm}$. After the extrusion, the extrudate was cooled in water bath and palletized. Finally these granules were injection molded as per ASTM using SP130 injection molding machine (Windsor, India) having clamping force $100 \mathrm{~T}$ fitted with dehumidifier at a temperature range of $250-285^{\circ} \mathrm{C}$.

\subsection{Mechanical properties}

The tensile tests were performed according to ASTM D 638 using SHIMADZU AUTOGRAPH (model AG 50 RNISD MS) at room temperature of $23 \pm 1^{\circ} \mathrm{C}$. The gauge length was set as $50 \mathrm{~mm}$ and the cross head speed was $50 \mathrm{~mm} / \mathrm{min}$. Tensile strength, tensile modulus and elongation at break were recorded. The flexural properties of all the composites were measured with a Lloyd instruments Ltd, LR $100 \mathrm{KN}$, UK machine according to ASTM D 790 with a cross head rate of $2.82 \mathrm{~mm} / \mathrm{min}$. Izod impact strength was measured with a (ATS FAAR, Italy) impact tester according to ASTM D 256, method-A with notched samples. Five replicate specimens were used for each test and the data reported are the average of five tests.

MFI, as per ASTM D 1238 was carried out for all the PBT blend Nano composite samples. As per ASTM D 257, the volume resistivity was measured for all the samples prepared. The dielectric strength experiment was carried out as per ASTM D 149 on all the PBT blend nanotube composite samples.

\section{Results and discussion}

\subsection{Effect of loading PET on mechanical properties of PBT}

The mechanical properties, among all the properties of plastic materials, are often the most important properties because virtually all service conditions and the majority of end-use applications involve mechanical loading [20]. Impact strength is toughness and the property of plastics probably most useful to consider [21]. While it is possible to perform impact tests and to rank a series of plastic materials, it is impossible to predict whether the material will serve satisfactorily under the working conditions. The factors which may influence are additives, impurities, temperature, geometry, orientation and morphology, surface condition, energy and speed of any impacting blow, the environment and the strains due to external loads. PET was added in small weight proportions like $10 \%, 20 \%$ and $30 \%$ to PBT to watch out the changes in mechanical properties of PBT. 
The impact of PET on mechanical properties of PBT when added in different weight ratios are given in Table 1. It is evident from the Table 1 that Izod impact strength increases up to 80-20 weight ratio of PBT-PET and the increase is nearly 3.6 folds that of virgin PBT. Normally, PBT and PET are immiscible with each other as both belong to the same ester group and both are semi crystalline in nature. But without any added additives, blend of PBT and PET show improved mechanical property.

The values for tensile strength and flexural strength increases up to 80-20 weight ratio and then it decreases. Tensile modulus increases up to 80-20 weight ratio but 70-30 weight ratio shows only a slight variation from that of 80-20. Flexural modulus values also show the same trend as that of Izod impact strength, tensile strength and flexural strength. Thus, it is concluded that PBT-PET blends show optimised values for 80-20 weight ratio and this blended polymer exhibits better and improved mechanical properties.

\subsection{Effect of loading CNT with PBT-PET 80-20 blend}

Table 2 gives the mechanical property values obtained on loading CNT with PBT-PET 80-20 weight ratio. $0.15 \%, 0.30$ $\%$ and $0.45 \%$ weight ratios of CNT were added to PBT-PET 80-20 blend. The results show that the impact strength decreases on the addition of CNT to PBT-PET 80-20 blend. Both tensile strength and flexural strength are enhanced on the addition of CNT to PBT-PET 80-20 blend. Among the three nanotube composites, PBT-PET 80-20 blend loaded with $0.30 \% \mathrm{CNT}$ exhibits the maximum tensile strength and flexural strength.

The addition of CNT to PBT-PET 80-20 blend offers very little variation in the tensile modulus except $0.30 \%$ CNT nanotube composite which shows increase in the tensile modulus value. On contrast, addition of CNT to PBT-PET 8020 blend increases the flexural modulus value for all the three nanotube composites. For both tensile modulus and flexural modulus, $0.30 \%$ CNT exhibits the maximum value. The samples with CNT, have shown better results with tensile and flexural properties and compensated the loss due to impact strength. Ultimately, the sample with CNT should be regarded as tough as PBT-PET 80-20 blend. Study of thermal properties and morphology would reveal the inner structure of nanotube composites.

\subsection{Effect of loading CNT with PBT-PET 80-20 blend on MFI}

MFI measures the rate of extrusion of thermoplastic material through an orifice of specific length and diameter under prescribed conditions of temperature and pressure. MFI is primarily used as a means of measuring the uniformity of the flow rate of the materials. MFI is an inverse measure of molecular weight [22]. Table 3 gives the measured MFI values for the addition of CNT to PBT-PET 80-20 blend. MFI decreases for every addition of weight ratio of CNT. Since MFI is inversely related to molecular weight, carbon multi wall nanotube with high molecular weight reduces the viscosity as well as MFI.

\subsection{Electrical properties of PBT-PET 80-20 blend with CNT loading}

Carbon nanotubes are excellent conductors 18, 19. The electric current carrying capacity of nanotube is 1000 times higher than copper wire. Electrical properties were studied for the samples prepared with $0.15 \%, 0.30 \%$ and $0.45 \%$ weight ratios of carbon multi wall nanotubes.

The Table 3 shows that on incorporating CNT, the value of dielectric strength decreases emphasizing that carbon nanotubes are good conductors. The weight percentage ratio of carbon nanotubes is too small to impart any adverse changes. Nevertheless, the inclusion of carbon nanotubes has made its imprint by reducing the values of dielectric strength from the pure PBT or PBT-PET 80-20 blend.

From Table 3, it is observed that incorporation of CNT decreases the value of volume resistivity when compared with the pure PBT or PBT-PET 80-20 blend. This confirms the fact that the character of CNT has been imparted to the polymer blend taken. Thus, it is clear that CNT with good conducting properties can alter the electrical properties of the polymer sample incorporated to it. The sample with $0.45 \%$ of CNT shows marked decrease in the value of volume resistivity for the PBT-PET nanotube composites.

\section{Conclusion}

PBT/PET blend nanotube composites were prepared by employing melt compounding technique. Incorporation of PET to the PBT matrix increases the impact strength of the virgin matrix and tensile and flexural properties. However, incorporation of MWCNT along with PBT/PET increases tensile and flexural property by sacrificing impact strength in the blend matrix. CNT acts as nucleating agents and influences the rate of crystallisation and the crystallisation 
temperature of the semi crystalline polymer matrix. In case of PBT/PET blend nanocomposites, the storage modulus increased with the incorporation of the nanotubes. A slight improvement in the thermal stability of the PBT-PET 80-20 was noticed after the incorporation of the nanotube. XRD and TEM clearly show that clay has exfoliated and dispersed in PBT-PET blend matrix.

Table 1: Effect of loading PET with PBT on mechanical properties

\begin{tabular}{|c|c|c|c|c|c|c|}
\hline \multicolumn{2}{|c|}{$\begin{array}{c}\text { PBT/PET } \\
\text { weight ratio }\end{array}$} & $\begin{array}{l}\text { Izod impact strength } \\
\mathrm{J} / \mathrm{m}\end{array}$ & $\begin{array}{c}\text { Tensile strength } \\
\mathrm{MPa}\end{array}$ & $\begin{array}{c}\text { Flexural strength } \\
\mathrm{MPa}\end{array}$ & $\begin{array}{c}\text { Tensile } \\
\text { modulus GPa }\end{array}$ & $\begin{array}{c}\text { Flexural } \\
\text { modulus GPa }\end{array}$ \\
\hline & & 50 & 50 & 71 & 2.429 & 2.169 \\
\hline & & 133 & 61 & 79 & 2.779 & 3.203 \\
\hline & & 181 & 67 & 84 & 2.928 & 3.350 \\
\hline & & 179 & 63 & 81 & 2.937 & 3.259 \\
\hline Perce & ye weis & $\begin{array}{l}\text { Izod imp } \\
\text { strength }\end{array}$ & $\begin{array}{cc}\text { pact } & \text { Tensile } \\
\mathrm{J} / \mathrm{m} & \text { strength } \\
& \mathrm{MPa} \\
\end{array}$ & $\begin{array}{c}\text { Flexural } \\
\text { strength } \\
\mathrm{MPa}\end{array}$ & $\begin{array}{c}\text { Tensile } \\
\text { modulus } \\
\text { GPa }\end{array}$ & $\begin{array}{c}\text { Flexural } \\
\text { modulus } \\
\mathrm{GPa}\end{array}$ \\
\hline PBT & PET & CNT & & & & \\
\hline 80 & 20 & 181 & 67 & 84 & 2.9 & 3.33 \\
\hline 80 & 20 & 0.15 & 69 & 94 & 2.8 & 4.20 \\
\hline 80 & 20 & 0.30 & 73 & 105 & 3.7 & 4.85 \\
\hline 80 & 20 & 0.45 & 70 & 100 & 2.9 & 4.59 \\
\hline $\begin{array}{r}\text { PBT p } \\
\text { weig }\end{array}$ & $\begin{array}{l}\text { ntage } \\
\text { atio }\end{array}$ & $\begin{array}{l}\text { PET percentage } \\
\text { weight ratio }\end{array}$ & $\begin{array}{l}\text { CNT percentage } \\
\text { weight ratio }\end{array}$ & $\begin{array}{l}\text { Melt flow index } \\
\mathrm{g} / 10 \mathrm{~min}\end{array}$ & $\begin{array}{c}\text { Volume } \\
\text { resistivity hm.cm }\end{array}$ & $\begin{array}{c}\text { Dielectric } \\
\text { strength } \mathrm{KV} / \mathrm{mm}\end{array}$ \\
\hline & & 0 & 0 & 43.6 & $6.2 \times 10^{16}$ & 16.00 \\
\hline & & 20 & 0 & 31.7 & $6.4 \times 10^{16}$ & 19.80 \\
\hline & & 20 & 0.15 & 28.8 & $2.0 \times 10^{14}$ & 15.31 \\
\hline & & 20 & 0.30 & 17.3 & $8.0 \times 10^{13}$ & 14.21 \\
\hline & & 20 & 0.45 & 12.4 & $5.0 \times 10^{13}$ & 12.74 \\
\hline
\end{tabular}

\section{References}

[1] Mishra, S. P. and Deopure, L., Polymer Bull. 26, (1985) 5.

[2] Yu, Y. and Choi. K., Polym. Engg. Sci. 37, (1997) 91.

[3] Nabisaheb, D. and Jog, J. P., Polym. Sci. Part B, Polym. Phys. 37, (1999) 2439.

[4] Avramova, N., Polymer, 36, (1995) 801.

[5] Wfer, J. M., US Patent, 485, (1984) 212.

[6] Pratt, C. F., Phadke, S. V. and Oliver, E., US Patent, 965, (1990) 111.

[7] Lim, J. W., Hassan, A., Rahmat, A. R. and Wahit, M. U., Polym. Int. 55, (2006) 204.

[8] Mark, H. F., Bikales, N. M., Overberger, C. G., Menges, G. and Kroschuritz, J. I. (1986). Encyclopedia of polymer Science and Engineering, (Wiley, New York), pp 12.

[9] Van Berkel, R. W. M., Van Hartigsveldt, E. A. A. and Van der Sluijs, C. L. (1997). In: Olalrisi O, Ed. Handbook of thermoplastic, (Marcel Dekker, New York), Ch. 20.

[10] Jadhav, J. Y. and Kantor, S.W. (1985). Thermoplastic Polyesters in encyclopedia of Polymer Science and engineering, (Wiley, New York), 2nd Ed, pp 12.

[11] Flexman, E. A., Polym. Engg. Sci. 19, (1979) 564

[12] Hourston, D. J. and Lang, S. (1994). Rubber Toughened Engineering Plastics, Ed. A.A.Collyer, (Chapman and Hall, London).

[13] Gaymans, R. J., In: Paul, D. R. and Bucknall, C. B. (2000). Editors. Polymer blends, (Wiley, New York), Ch. 25, pp 2

[14] Kojima, Y., Usuki, A., Kawasumi, M., Okada, A., Fukushuma, Y., Kurauchi, T. and Kamigaito, O., J Mater Res. 8, (1993) 1185

[15] Wang X, Li Q, Xie J, Jin Z, Wang J, Li Y, Jiang K, Fan S, Nano letters, 9, (2009) 3137.

[16] Yu, Min-feng, Lourie, Oleg, Dyer, Mark J, Moloni, Katerina, Kelly, Thomas F, Ruoff, Rodney S, Science, $287(5453)$, (2000) 637.

[17] Popov M et al., Physics Rev. B, 2002, 65.

[18] Mintmire J W, Dunlap B I, White C T, Physical Review Letters, 1992, 68 (5), 631.

[19] Dekker, Cees, Physics today, 52, (1999) 22.

[20] Vishu Shah, (1984). Handbook of Plastics Testing Technology, (John Wiley, New York), pp 8.

[21] Rodriguez, F. (1970). Principles of Polymer Systems, (McGraw-Hill, New York), Ch.8.

[22] Brydson, J. A. (2005). Plastics Materials, 7th Edn. (Butterworth and Heinemann, Oxford), pp 73 